\title{
APLIKASI KACA PADA PERANCANGAN DESAIN INTERIOR DAN ARSITEKTUR
}

\author{
Grace Hartanti; Budi Setiawan \\ Interior Design Department, School of Design, BINUS University \\ Jln. K.H. Syahdan No. 9, Palmerah, Jakarta Barat 11480 \\ ghartanti@binus.edu \& bsetiawan@binus.edu
}

\begin{abstract}
Glass is a clear and see-through material that comes from SiO2, which is a form of sands heated to $2000^{\circ} \mathrm{C}$ until they are melted. Glass has its own characteristics, such as: hard, transparent, clear, and fragile. The use of glass can be applied in a wide range of building elements, for example: roofing, walling, flooring, window and door, even staircase elements. By this wide range of utilities, this material could be very useful in design process. It can provide a wider view for small room with a lot of partitions or wall. It is because this material allows the light passing trough the material. That's why people are able to see what's behind the glass and eyes can see-through although the glass wall is limited by the glass. Hopefully, the research about diversity of glasses will be useful for designer, architect, and community in interior design and architecture world.
\end{abstract}

Keywords: glass, building materials, glass application on design elements

\begin{abstract}
ABSTRAK
Kaca merupakan materi bening dan transparan (tembus pandang) yang dihasilkan dari SiO2 (dalam kimia disebut dengan kwarsa), yaitu pasir yang dilelehkan hingga mencapai suhu $2000^{\circ} \mathrm{C}$. Sifat-sifat kaca adalah keras, transparan, bening, dan dapat pecah. Penggunaan kaca dapat diaplikasikan di berbagai elemen bangunan, di antaranya dapat digunakan untuk atap, dinding, lantai, jendela, pintu, dan anak tangga. Kaca memiliki berbagai spesifikasi yang bervariasi sehingga memudahkan penggunaan untuk berbagai keperluan. Pengaplikasian kaca memungkinkan pandangan menjadi lebih luas dan tidak terbatas. Hal ini dapat menimbulkan kesan terbuka dan bebas yang karena kaca merupakan material bangunan yang memungkinkan seseorang melihat sesuatu di baliknya, sehingga mata dapat melihat lebih jauh meskipun secara ruang terbatasi oleh kaca tersebut. Diharapkan, melalui penelitian tentang keberagaman kaca ini dapat berguna bagi desainer, arsitek, dan masyarakat dalam berkarya di dunia desain interior dan arsitektur.
\end{abstract}

Kata kunci: kaca, bahan bangunan kaca, aplikasi kaca pada perancangan desain 


\section{PENDAHULUAN}

Perkembangan dalam dunia Desain Interior dan Arsitektur meningkat demikian cepat, terutama pada negara berkembang seperti Indonesia. Dengan meningkatnya perkembangan teknologi, kaca sudah memiliki variasi yang dapat membantu proses perencanaan dan perancangan Desain Interior dan Arsitektur. Sejarah kaca (Ahmad, 2007) berawal dari tahun 3000 SM, Bangsa Syria menemukan cara pembuatan kaca dengan mencampur abu soda, lemon, dan pasir yang akhirnya membentuk kaca pada saat masih panas.

Tahun 1400 SM, Mesir sudah membuat vas dan peralatan makan dengan menggunakan unsur kaca di dalamnya. Kaca sudah dipercantik dengan penambahan warna pada permukaan dan kaca tiup mulai ditemukan dengan menggunakan pipa metal untuk meniup. Pada 1291 Roma menggunakan kaca sebagai jendela, cahaya dapat masuk tetapi orang tidak bisa melihat keluar. Di kepulauan Hali, masih di wilayah Roma teknik kaca Murano ditemukan, yaitu berupa kaca bening dan hampir transparan umum disebut dengan "cristallo”, namun lebih dikenal dengan kaca Murano.

Abad ke-14 merupakan zaman kekaisaran Romawi, dengan kota Venesia menjadi pusat produksi kaca. Namun dengan keruntuhan Romawi, tempat pengolahan kaca berpindah ke daerah timur, yaitu Syria dan Byzantium. Pada abad ke-16 Inggris mulai menemukan bahwa menggunakan batu bara dalam proses pembuatan kaca akan menghasilkan kaca yang lebih bening. Pada 1688, Louis Lucas de Nehon, seorang berkebangsaan Prancis membuat proses manual membuat piring kaca dan membutuhkan waktu 16 hari untuk menghasilkan kaca yang baik.

Pada abad ke-19 perkembangan teknologi memungkinkan untuk memproduksi kaca dalam skala besar dengan menggunakan abu soda dan abu ganggang sebagai bahan kayu bakar sehingga temperatur tinggi mudah dicapai. Pada 1959 Pilkington Brothers di London, Inggris, menemukan float glass, yaitu berupa sebuah proses penyempurnaan produksi kaca. Kaca pertama kali diperkenalkan oleh Belanda, yang penggunaannya terbatas pada bangunan milik kalangan tertentu saja karena dianggap sebagai barang yang berkelas, antara lain pada istana, keraton, gereja, rumah pejabat Belanda.

Saat ini kaca menjadi salah satu material yang banyak menghiasi bangunan-bangunan di Indonesia. Adapun penelitian ini bertujuan untuk membuka wawasan akan keberagaman kaca dengan variasi yang ada saat ini sudah beragam banyaknya. Diharapkan, keberagaman material kaca ini dapat membantu desainer dan arsitektur pada khususnya dan masyarakat pada umumnya untuk berkarya lebih lagi dalam menggunakan material kaca.

\section{METODE}

Metode yang digunakan pada penelitian ini bersumber pada literatur cetak (melalui buku referensi pendukung mengenai bahan bangunan terutama yang mengangkat topik kaca) maupun elektronik (melalui media Internet). Selain itu, penelitian melakukan survei lapangan dan wawancara dengan pihak penghasil dan supplier material kaca serta pihak-pihak terkait lainnya. 


\section{HASIL DAN PEMBAHASAN}

\section{Jenis-jenis Kaca}

Perkembangan desain dan teknologi telah menghasilkan kaca dengan beragam bentuk maupun warna, namun jenis kaca secara umum terbagi menjadi sebagai berikut (Ahmad, 2007).

\section{Flat Glass}

Tipe kaca ini yang paling umum dilihat di sekitar. Umumnya juga disebut dengan clear glass. Sifat dari kaca jenis Flat Glass ini adalah transparan dan colourless (tidak berwarna) sehingga meneruskan cahaya 75-92\%. Ukuran kaca Flat Glass yang berada di pasaran adalah 2,00x3,00 meter dengan ketebalan yang umum digunakan pada perencanaan interior maupun furnitur mulai dari $3 \mathrm{~mm}$ $16 \mathrm{~mm}$ (umumnya berukuran $3 \mathrm{~mm}, 5 \mathrm{~mm}, 6 \mathrm{~mm}, 10 \mathrm{~mm}, 12 \mathrm{~mm}, 16 \mathrm{~mm}$ ).

Penambahan warna juga dapat dilakukan pada kata Flat Glass. Umumnya warna yang dipakai adalah tembaga, abu-abu, hijau, dan biru. Hal ini bertujuan untuk mengurangi banyaknya cahaya yang masuk karena kaca dapat menyerap cahaya matahari. Makin tebal kaca, makin membutuhkan pewarna untuk menyerap cahaya.

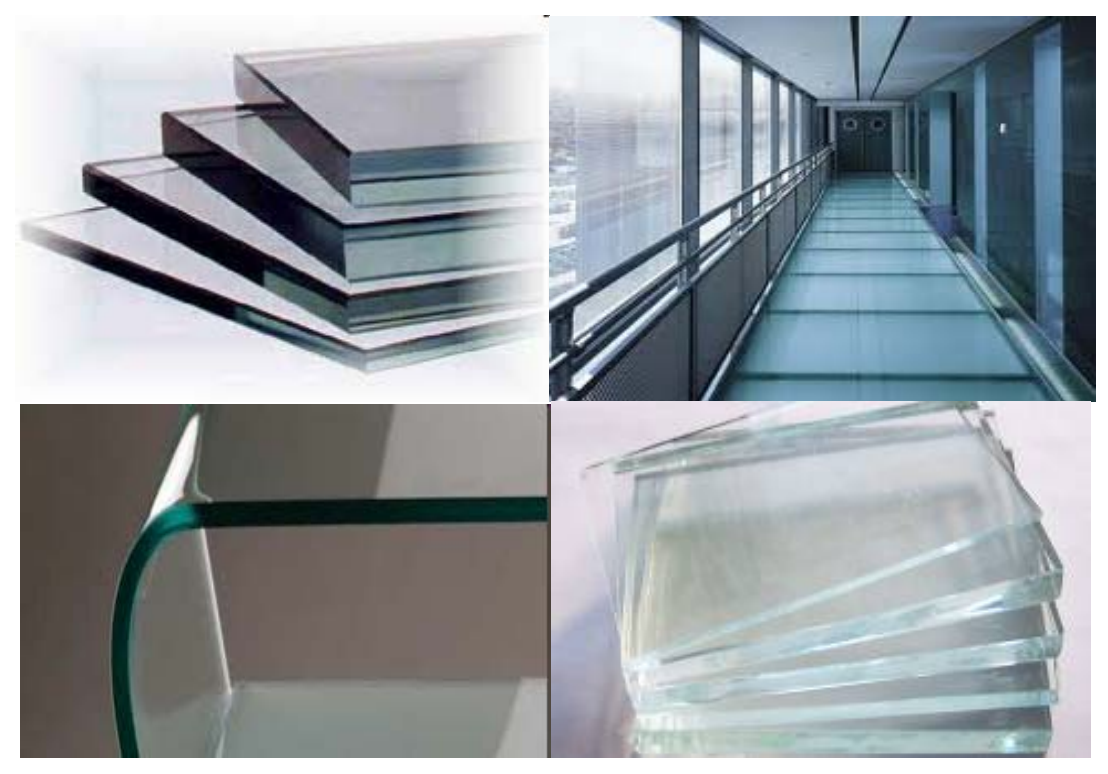

Gambar 1 Flat Glass

\section{Safety and Security Glass}

Kaca yang diproduksi dengan tujuan kemanan dan keselamatan. Kaca ini ditempatkan, digunakan untuk mengurangi resiko terluka akibat dari rusak/hancurnya kaca. Pertama, wired glass, kaca dengan jalinan kawat di dalamnya, yang dibuat dengan memasukkan kawat di antara lapisan kaca pada proses produksinya. Wired glass mempunyai fungsi yang hampir sama dengan kaca standar. Hanya pada saat pecah, jalinan kawat tidak akan ikut pecah sehingga masih menahan benda untuk masuk ke dalam, contoh: glass door, glass roof. 


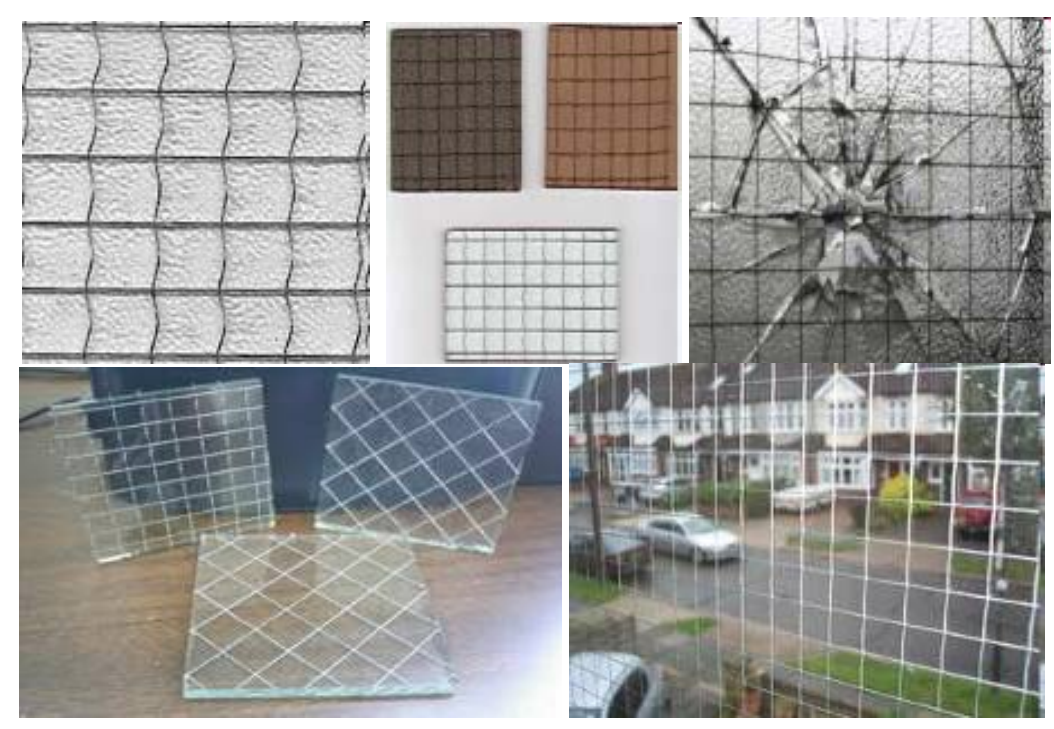

Gambar 2 Wired Glass

Kedua, laminated glass. Jenis safety glass ini tidak hancur jika terbentur. Laminated glass ditemukan pada 1903 oleh ahli kimia dari Prancis bernama Edward Benedictus yang terinspirasi dari kecelakaan laboratorium. Laminated glass digunakan untuk menghindari kecelakaan kendaraan dengan kaca dilapisi dengan sejenis plastik bernama Polyvinyl Butyral (PVB). Pada proses laminated glass, material seperti kain, kayu sampai dengan metal dapat diisi di antara 2 lapisan kaca, yang akan menghasilkan efek visual yang unik dan ideal sebagai pembatas ruangan yang menarik. Contohnya partisi kaca, pintu kaca, kaca dekoratif.
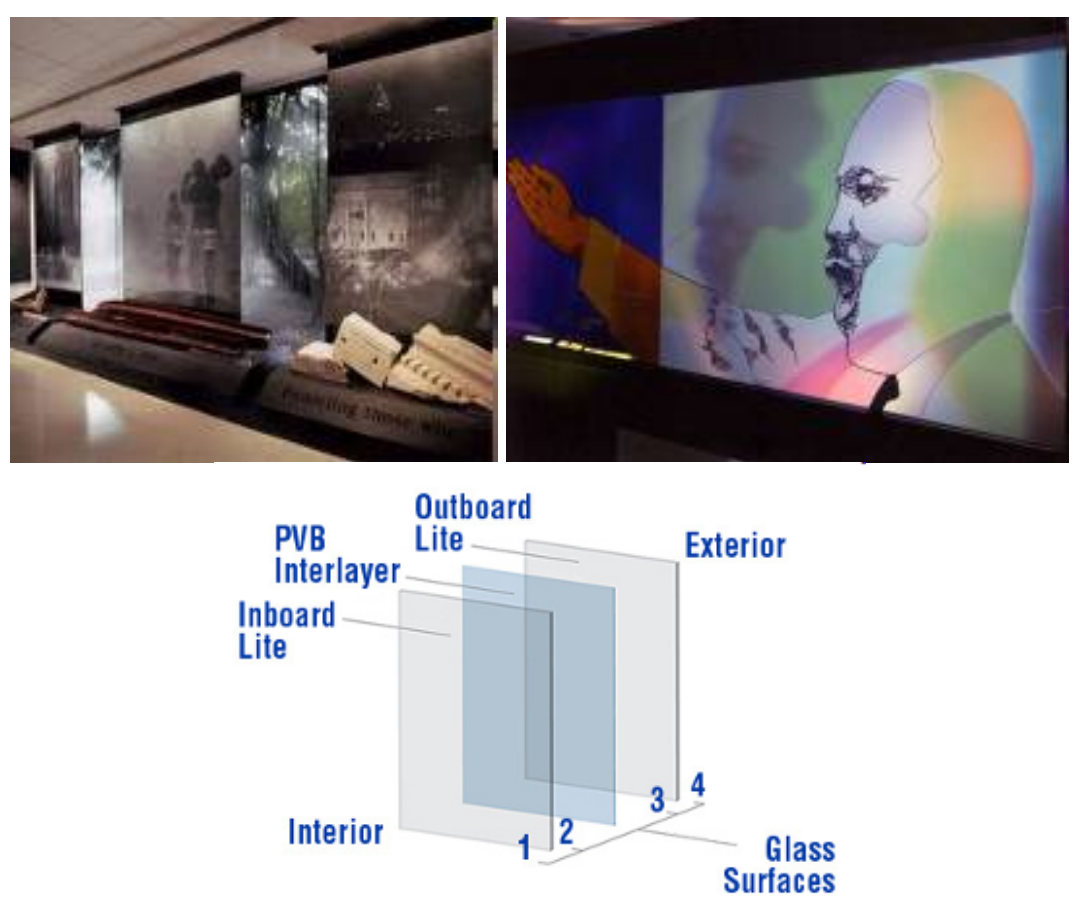

Gambar 3 Laminated Glass 
Ketiga, tempered glass merupakan salah satu jenis safety glass yang umum digunakan sebagai kaca standar yang diperuntukan area yang berisiko tinggi. Sifat tempered glass (Akmal, 2009): tahan panas, tahan terhadap benturan ringan, 4-5 kali lebih kuat dari kaca standar, kaca tempered akan pecah dalam bentuk serbuk halus dan tidak dalam bentuk yang tajam. Ukuran tempered glass yang berada di pasaran mulai dari $3 \mathrm{~mm}-18 \mathrm{~mm}$.

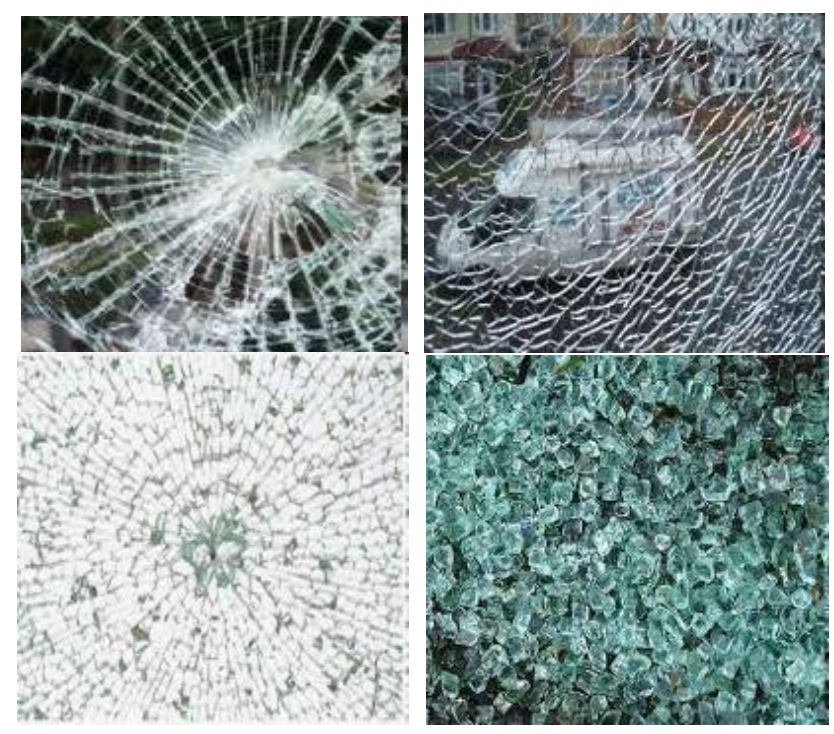

Gambar 4 Tempered Glass

Keempat, reflective glass, merupakan jenis kaca yang biasa digunakan untuk eksterior bangunan. Kaca ini mempunyai daya tembus satu arah sehingga kegiatan di dalam ruang tidak tampak dari luar. Reflective glass mempunyai ketebalan mulai dari 5, 6 sampai $8 \mathrm{~mm}$. Reflective glass mempunyai lapisan metal yang berfungsi untuk mengurangi panas ultraviolet, yang menghasilkan efek memantul.

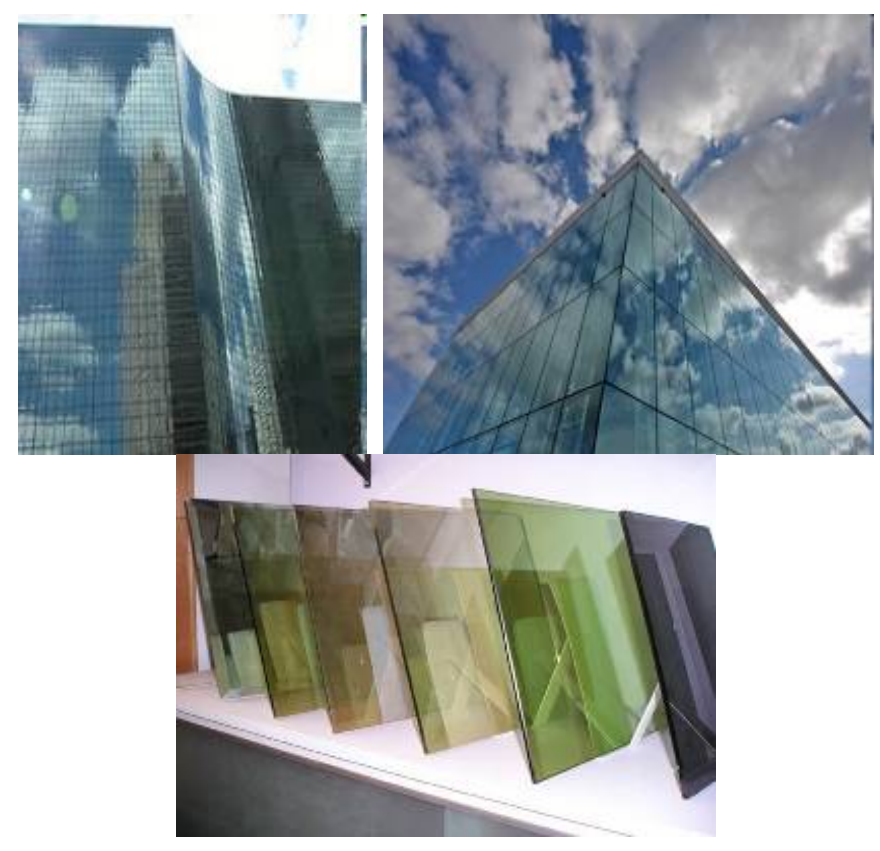

Gambar 5 Reflective Glass 
Kelima, glass block, merupakan bahan bangunan yang bisa terlihat rapuh dan kokoh secara bersamaan. Kelebihan penggunaan glass block adalah cahaya alami dapat tetap masuk ke ruangan mengurangi suara yang masuk, tidak perlu dicat, dan mudah dibersihkan. Ukuran glass block: 6x6x4 inci; 8x8x4 inci; 12x12x4 inci; 6x8x4 inci. Dengan catatan, ukuran dalam 1 inci adalah 2,5 cm. Tipe glass block yang umum di pasaran adalah see trough (tembus pandang), frosted (buram), random wave (bergelombang), vertical/horizontal rib (pola teratur), crystallin, leather, Grid.

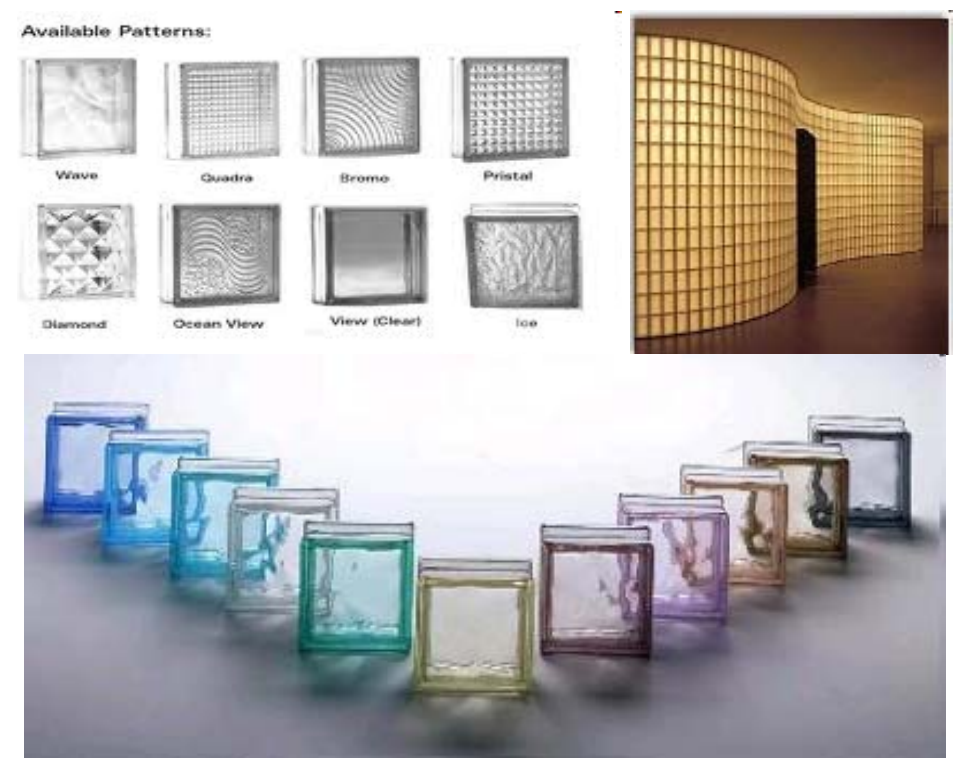

Gambar 6 Glass Block

\section{Speciality glass}

Speciality glass merupakan jenis-jenis produk kaca yang dihasilkan dengan bentuk dan fungsi yang berbeda. Pertama, mozaik merupakan seni membuat/menciptakan karya dengan menyatukan bentuk-bentuk kecil menjadi sebuah pola atau gambar. Dalam hal ini, material yang digunakan bisa kaca ataupun batu, yang umumnya berbentuk bujur sangkar ukuran kecil dengan warna yang beragam.

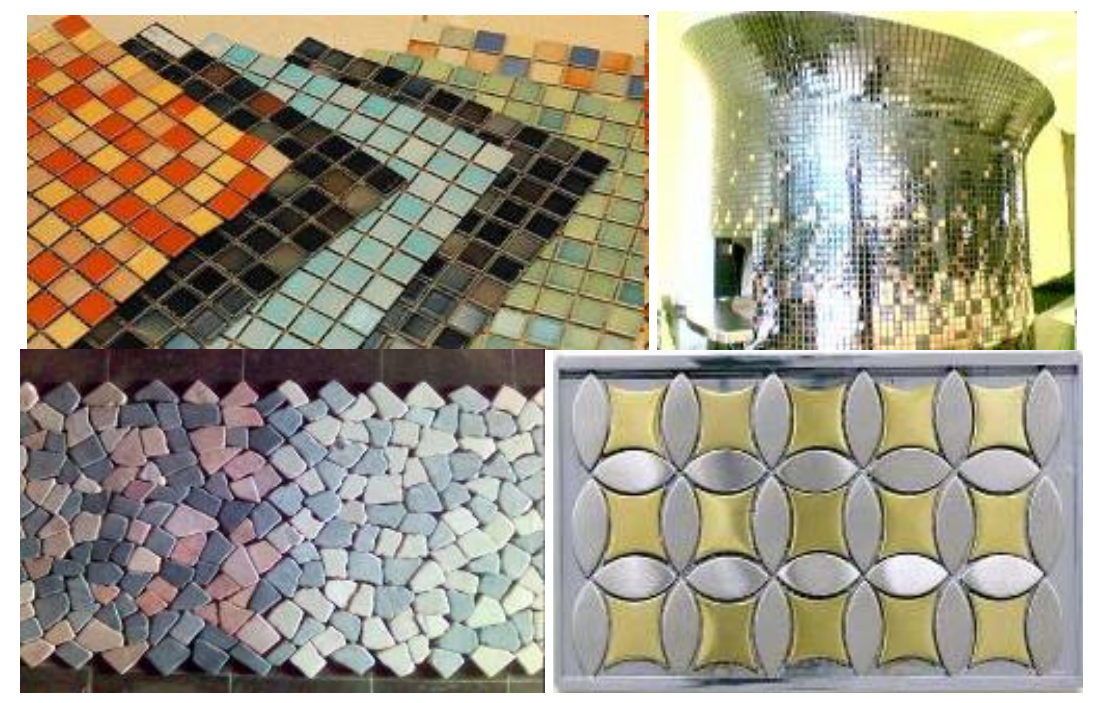

Gambar 7 Mozaik 
Kedua, mirror. Cermin mempunyai permukaan memantul yang cukup licin untuk membuat bayangan. Pertama kali ditemukan cermin obsidian di Anatolia (sekarang Turki) terbuat dari kepingan batu obsidian (batu mengkilap). Cermin modern terdiri atas lapisan aluminium disalut dengan kepingan kaca sehingga membalikkan pantulan benda sampai dengan $80 \%$ dari cahaya yang datang. Bagian belakang cermin dicat hitam untuk melindungi logam dari pengikisan.

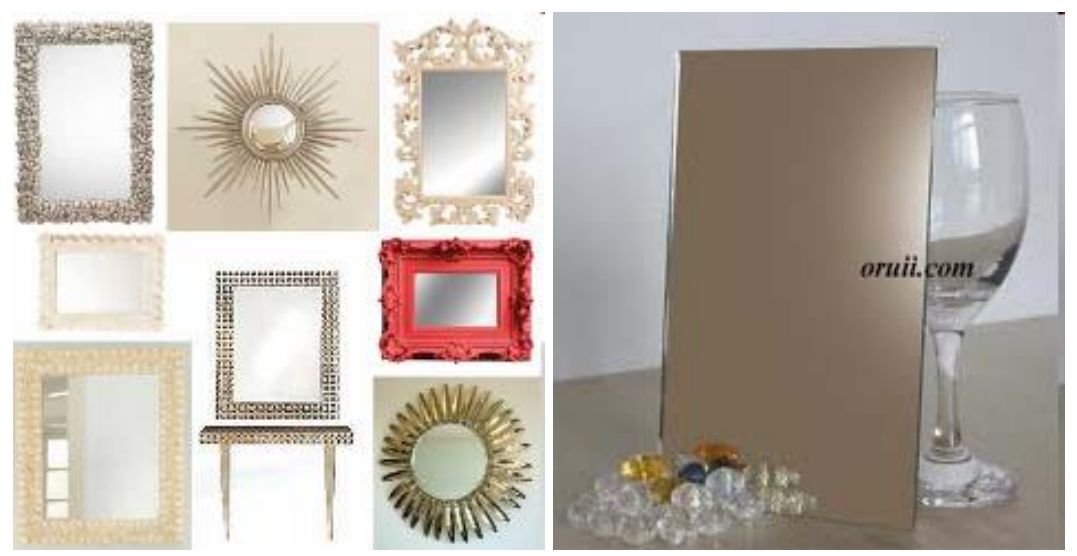

Gambar 8 Mirror

Ketiga, blowing glass, merupakan teknik pembentukan kaca dengan cara menggembungkan kaca yang masih dalam bentuk cair menjadi gelembung dengan menggunakan alat tiup. Peniup alat ini disebut dengan glassblower. Banyak digunakan untuk produksi vas, aksesoris rumah dll. Warna dan bentuk sangat beragam tergantung dari keahlian dan keterampilan pembuat, dimana bentuk kaca dibuat pada saat kaca masih dalam kondisi yang sangat panas.
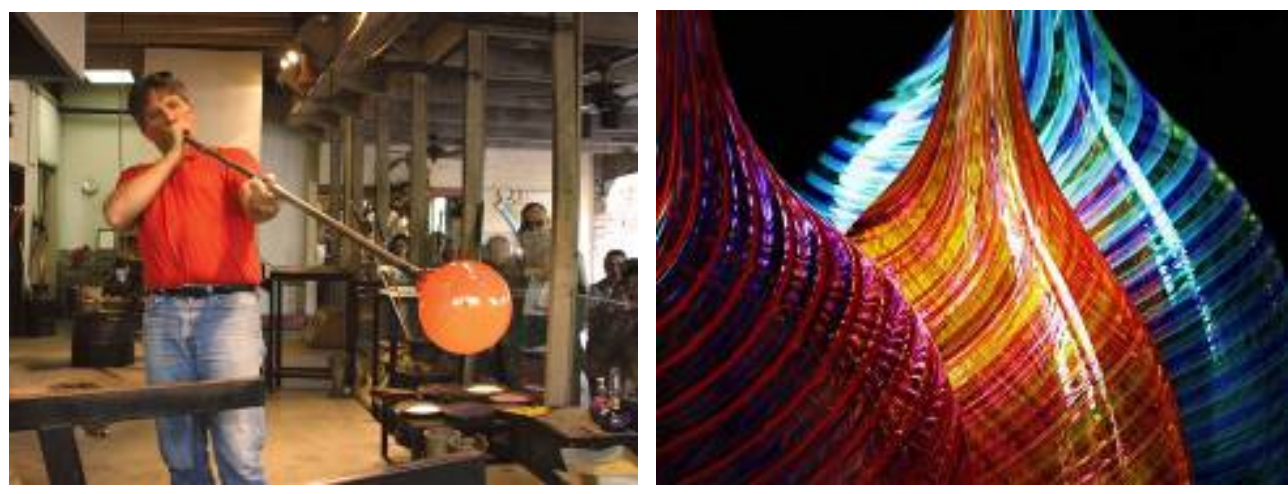

Gambar 9 Blowing Glass

\section{Decorative Glass}

Pertama, patterned glass, tersedia dalam berbagai warna, mempunyai permukaan yang tidak halus dengan pola yang berbeda dan hanya sedikit meneruskan cahaya (Martin, 2005). Fungsi dari patterned glass, antara lain dapat mengatur cahaya yang masuk; mengaburkan pandangan akan benda (bersifat translucent); dan elemen estetis. Patterned glass diproduksi dengan menggunakan rolled glass proses, yaitu adonan bahan kaca yang masih lunak ditekan di antara 2 mesin beroda, yang ketebalan kaca bisa diatur dengan menentukan jarak antara 2 mesin tersebut. 


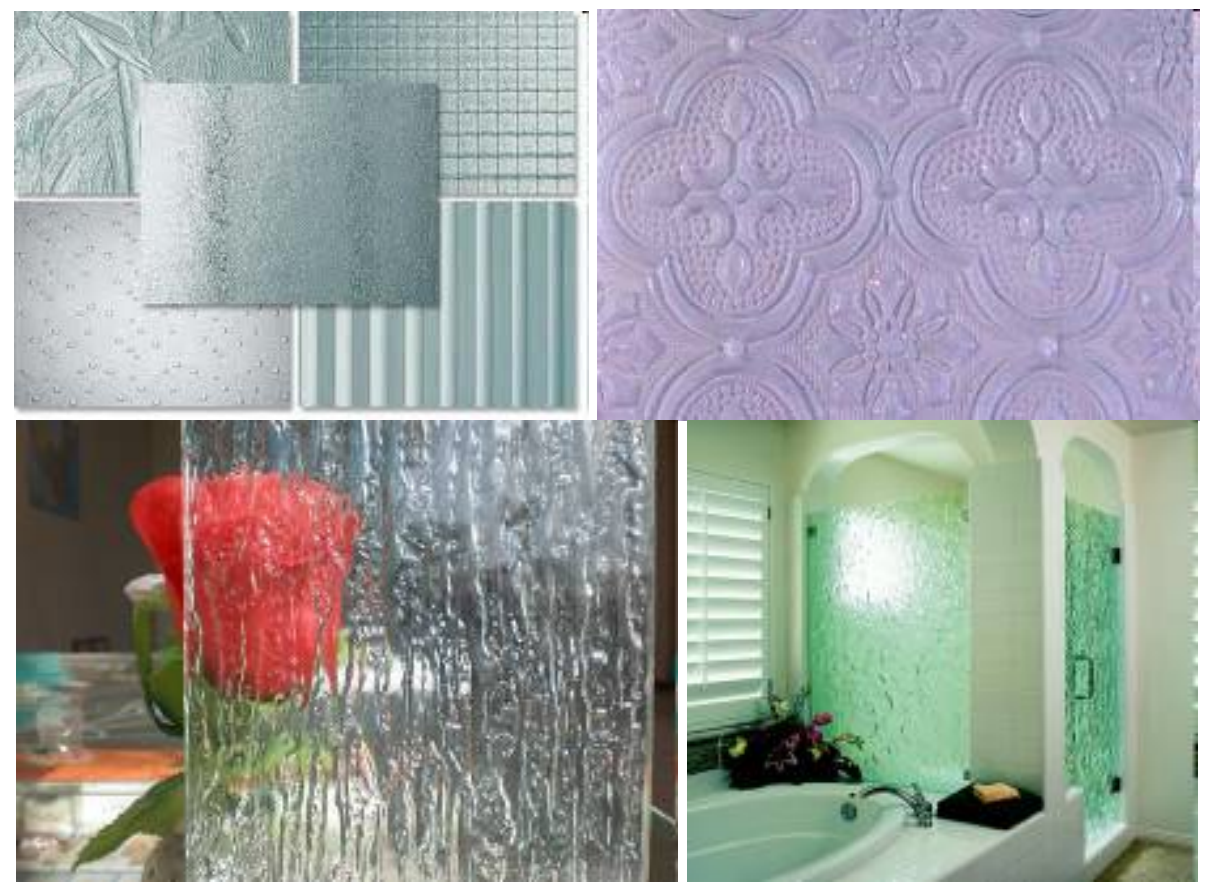

Gambar 10 Patterned Glass

Kedua, sand blasted glass, diproduksi dengan menyemprotkan pasir dengan kecepatan yang sangat tinggi ke permukaan kaca, sehingga kaca menjadi buram. Proses sandblasting ini cukup berbahaya untuk sistem pernapasan karena dapat mengakibatkan Silicosis (salah satu jenis penyakit paru-paru). Sebagai alternatif dari kondisi tersebut, saat ini sudah umum digunakan cutting stiker. Kaca ditempel dengan stiker dengan ragam pola maupun tekstur yang dapat disesuaikan dengan kebutuhan desain (Akmal, 2009). Penerapan sandblasted glass dapat dilihat pada pintu, partisi, partisi shower, interior screen, furnitur, dan lain-lain.
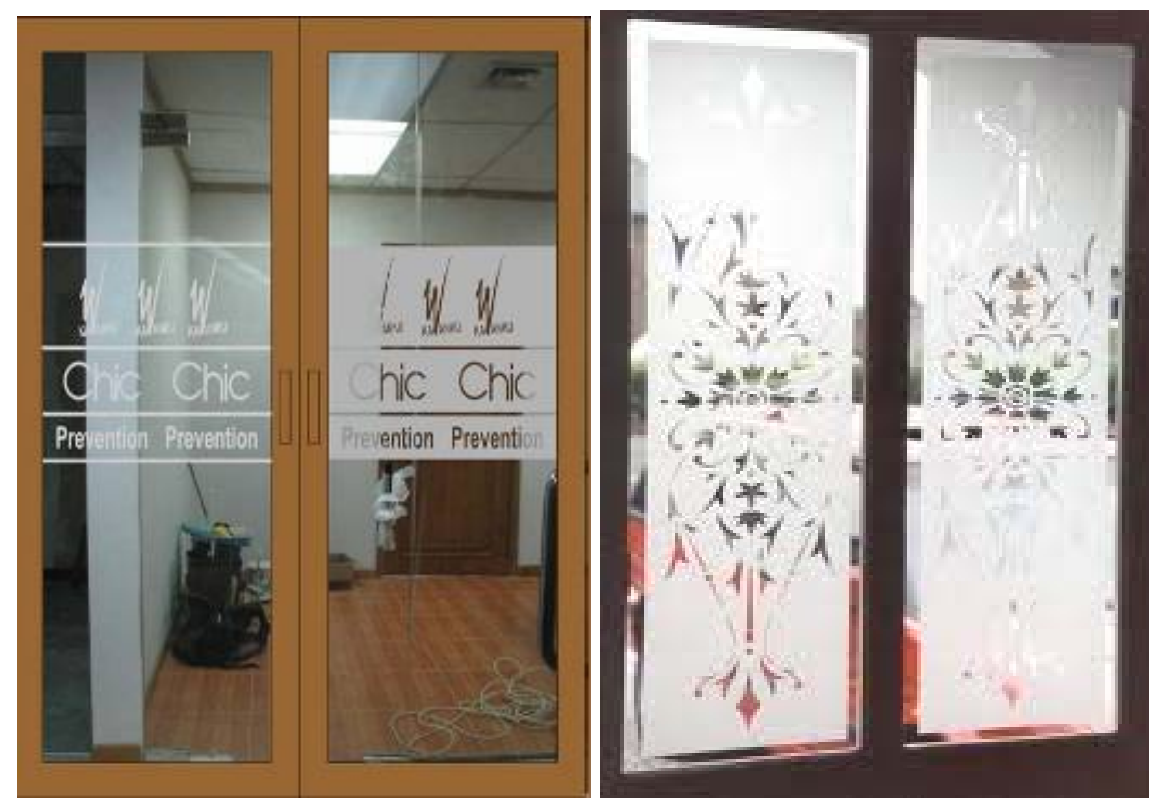

Gambar 11 Sandblast Glass 
Ketiga, etched glass (kaca grafir), merupakan seni menghias, melukis, atau mengukir yang didasari dengan menggunakan media kaca, yaitu dengan membuat pola atau gambar pada kaca dengan menggunakan acid product yang biasanya dibuat pada float glass. Kaca grafir ini mempunyai efek yang sangat halus dengan ornamen dekoratif yang beragam (Martin, 2005).
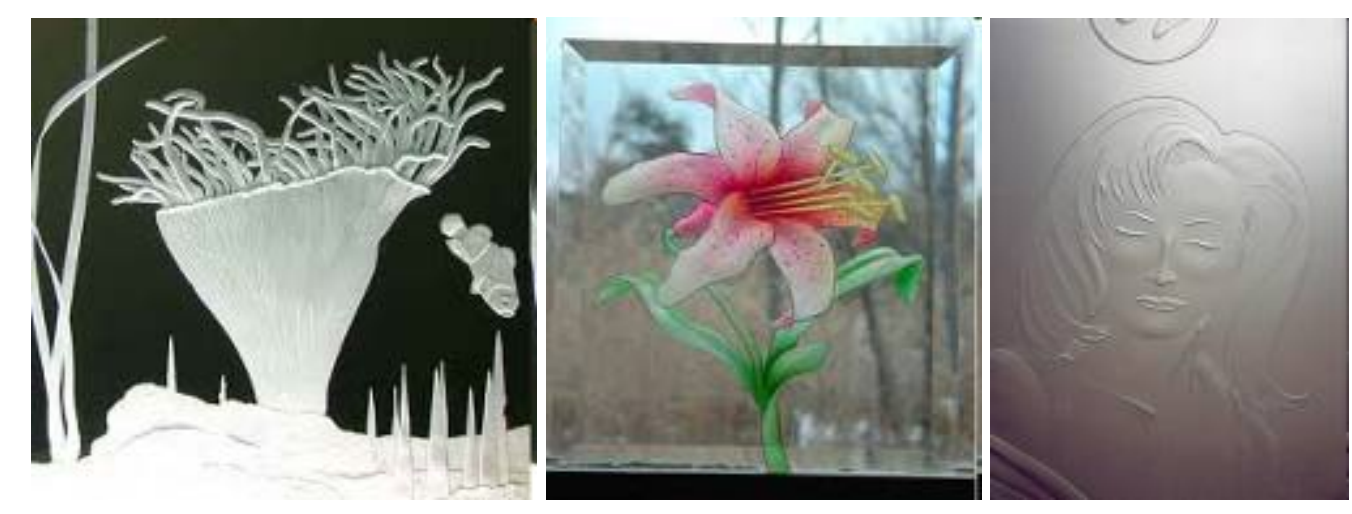

Gambar 12 Etched Glass

Keempat, stained glass (kaca patri), merupakan material kaca berwarna, disusun dari kacakaca berukuran kecil yang diatur sedemikian rupa sampai membentuk pola atau gambar tertentu, disambung secara manual dengan menggunakan timah. Pewarnaan dilakukan dengan menambah unsur logam, misalnya: copper untuk warna hijau, cobalt untuk warna biru, dan gold untuk warna merah. Kaca patri berasal dari Eropa, dikenal pada abad pertengahan abad 12, yaitu zaman Gotik (merupakan puncak kejayaan seni kaca patri).
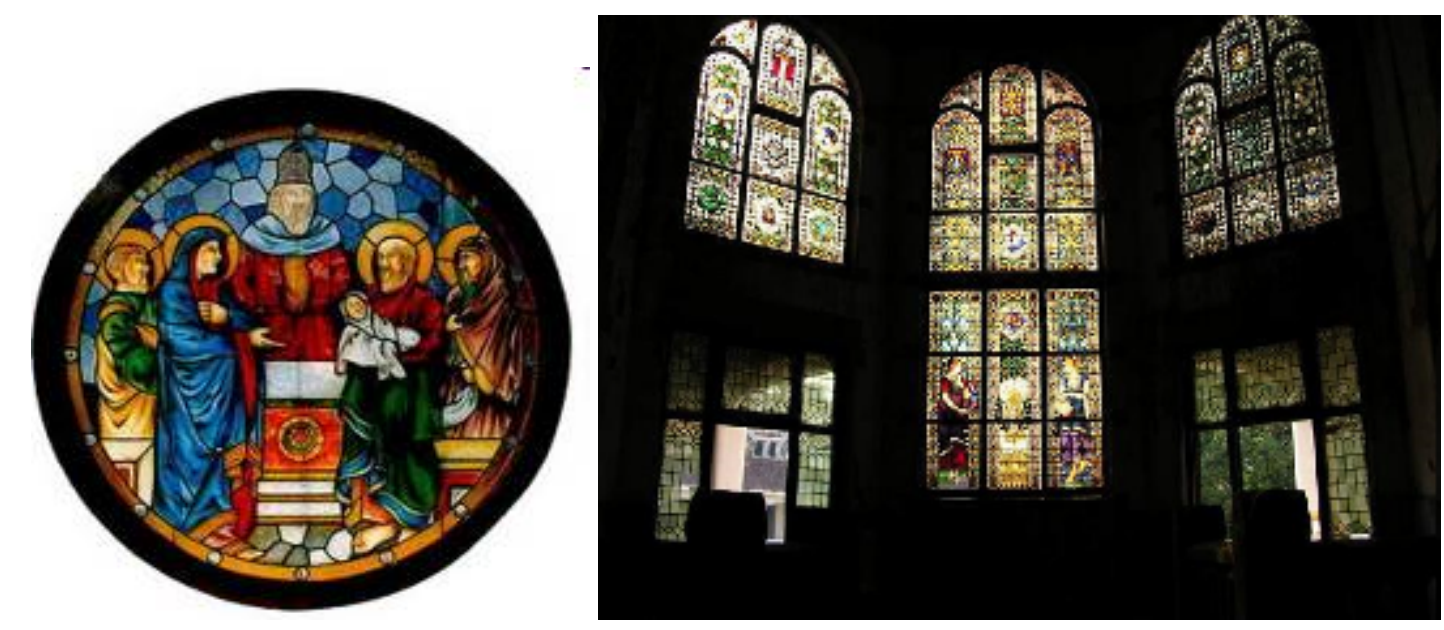

Gambar 13 Stained Glass 


\section{SIMPULAN}

Perkembangan kaca yang demikian pesat sejalan dengan perkembangan teknologi memungkinkan seseorang untuk lebih mudah mendapatkan kaca dengan keanekaragaman spesifikasi dan jenisnya. Pada zaman modern ini, kaca menjadi salah satu material yang diminati oleh masyarakat. Kaca banyak diaplikasikan pada elemen-elemen interior di antaranya di lantai, dinding, ceiling, jendela, pintu, dan anak tangga. Keragaman jenis-jenis kaca juga memungkinkan seorang untuk mendapatkan berbagai variasi tampilan desain yang dibutuhkan. Hal ini dapat membawa banyak keuntungan terutama dalam dunia arsitektur dan desain interior dalam melakukan perancangan (Hamlyn, 2007).

Terus berkembangnya teknologi dan ilmu pengetahuan secara umum dan desain pada khususnya diharapkan akan terus membawa kebaharuan terhadap bahan bangunan yang ada. Dalam hal ini, kaca merupakan salah satu contoh bahan bangunan yang perkembangannya terus bergerak maju dari masa ke masa. perkembangan ini diharapkan terus membawa dampak positif bagi semua pihak pada umumnya dan perkembangan dunia arsitektur dan desain interior pada khususnya.

\section{DAFTAR PUSTAKA}

Ahmad, R. (2007). Bahan Bangunan sebagai Dasar Pengetahuan. Edisi Pertama. Jakarta: BCPU.

Akmal, I. (2009). Seri Rumah Ide: Kaca dan Fiber Glass. Edisi Pertama. Jakarta: Gramedia.

Hamlyn. (2007). How to Decorate. 1st Edition. London: OCTOP.

Martin, C. (2005). The Surface Texture Bible. 10th Edition. New York: ABRA.

Wardoyo, R. (2010). Jurnal Pengaturan Intensitas Cahaya pada Rumah Kaca. Pusat Penelitian Informatika (LIPI). 